\title{
Diagnóstico ultrassonográfico de hidropisia fetal intrauterino - relato de caso
}

\section{Sonografhic diagnosis of fetal hidrops intrauterine - case report}

\section{Resumo}

A hidropisia fetal é uma doença caracterizada pelo acúmulo anormal de liquido extravascular nos tecidos ou nas cavidades do corpo. Em humanos o diagnóstico é realizado durante o exame ultrassonográfico no pré-natal. Este estudo tem como objetivo reportar o diagnóstico intrauterino de hidropsia fetal em um feto de Poodle num período avançado da gestação, durante um exame ultrassonográfico pré-natal onde foi detectado a presença de efusão pleural e peritoneal. Os achados ultrassonográficos foram confirmados no exame pós-morte do feto.

\section{Summary}

The Hydrops fetalis is a disease characterized by abnormal accumulation of extravascular fluid in the tissues or body cavities. In human medicine the diagnosis is usually performed during the prenatal ultrasound examination. This study aims to report the intrauterine diagnosis of fetal hydrops in a fetus of a Poodle dog. In a late prenatal ultrasound the presence of pleural and peritoneal effusion were detected. The ultrasound findings were confirmed in the post-mortem examinations. 
Tatiane Marchetti Da Silva ${ }^{1}$

Renata Dos Santos Zakimi ${ }^{1}$

Pâmela Diniz Garcia ${ }^{1}$

Helder Esteves Thomé ${ }^{2}$

Maria Lúcia Gomes Lorenço ${ }^{3}$

Jefferson Douglas Soares Alves ${ }^{4}$
Rua dos Jacarandás, 544, apto 23 - Jd. São

Paulo - Americana (SP) - CEP 13468-050

ه tatiane_marchetti@hotmail.com
Palavras-chave

Cão. Anasarca. Pré-natal.

\section{Keywords}

Canine. Prenatal. Anasarca.

\section{Introdução}

A hidropisia é uma enfermidade caracterizada pelo acúmulo anormal de líquido seroso em tecidos e ou cavidades do corpo e pode ser dividida em três tipos: hidropisia dos envoltórios fetais (hidroalantóide/ hidroâminio), do feto e, ou da placenta (comum em ruminantes). Essas três possibilidades podem ocorrer separada ou isoladamente mesmo não havendo relação entre elas (TONIOLLO; VICENTE, 2003). A hidropsia fetal, da qual esse trabalho relata, pode ser classificada em outros três tipos: efusão peritoneal, denominada ascite; anasarca ou Síndrome do filhote Morsa, que é o edema generalizado do tecido subcutâneo e hidrocefalia, que é um acúmulo de líquido no sistema ventricular ou entre o encéfalo; e a duramater comumente encontrado em suínos, bezerros e mais raramente em cães (TONIOLLO e VICENTE, 2003; LONG, 2001).

A hidropisia do tipo anasarca, em animais, é descrita como sendo causada por genes autossômicos recessivos e anomalias hipofisárias que resultam em edema generalizado do subcutâneo (TONIOLLO e VICENTE, 2003), excesso de líquido nas cavidades peritoneal e pleural, dilatação dos anéis umbilical e inguinal, bem como hidrocele e edema das membranas fetais (hidroalantóide) (LONG, 2001). Essas alterações em conjunto, foram relatadas em

1 M.V., residente Depto. Diagnóstico por Imagem - Centro Universitário da Fundação de Ensino Octávio Bastos- São João da Boa Vista - SP.

2 M.V., Prof. Depto. Patologia Animal - Centro Universitário da Fundação de Ensino Octávio Bastos São João da Boa Vista - SP.

3 M.V., Profa. Ass. Dra. Depto. Clínica Veterinária - Faculdade de Medicina Veterinária e Zootecnia Julio de Mesquita Filho - Botucatu - SP.

4 M.V., Prof. Ms. Depto. Diagnóstico por Imagem - Centro Universitário da Fundação de Ensino Octávio Bastos - São João da Boa Vista - SP. 
um bovino da raça Ayrshire (ARTHUR, 1979). As efusões pleural e pericárdica são citadas como alterações presentes em fetos humanos com hidropisia (SILVA et al. 2005).

A hidropisia do tipo efusão peritoneal normalmente está associada a um processo infeccioso (Brucella abortus) e a defeitos de desenvolvimento, tal como a acondroplasia (nanismo) e eventualmente pode ocorrer como causa primária (TONIOLLO e VICENTE, 2003). Porém, a anasarca é causada por anomalias genéticas (genes autossômicos recessivos) e/ou disfunção hipófise-adrenal (TONIOLLO e VICENTE, 2003, ARTHUR, 1979). O edema generalizado no subcutâneo, particularmente ocorre com mais intensidade na cabeça e membros pélvicos (LONG, 2001). A hidrocefalia normalmente está associada à deficiência de vitamina $\mathrm{A}$, agentes infecciosos e à fatores genéticos (TONIOLLO e VICENTE, 2003).

Os fetos acometidos pela hidropisia do tipo anasarca chegam a termo porém, normalmente causam distocias, devido ao excesso de líquido no tecido subcutâneo, sendo necessária, nestes casos, uma intervenção cirúrgica (cesariana) (LONG, 2001; ARTHUR, 1979; NOAKES, 2001; SORRIBAS, 2009). A distocia causada por monstruosidades patológicas é descrita em diferentes espécies animais, como bovinos (ARTHUR, 1979; NOAKES, 2001; ROBERTS, 1984), ovinos, suínos (NOAKES, 2001) e cães (SORRIBAS, 2009; ROBERTS, 1984; ALLEN, 1995; BUCHANAN, 2001).

Na população humana em geral, a ocorrência de hidropisia fetal é relativamente baixa, da ordem de 1/3.00o nascidos vivos, no entanto em grandes centros de referência em atendimento às gestantes de alto risco, a incidência é maior (SILVA et al., 2005). Na medicina veterinária a hidropisia fetal do tipo anasarca é descrita como de ocorrência rara, exceto na espécie bovina das raças Ayrshire (ARTHUR, 1979; ROBERTS, 1984) e Swedish Lowland; e na espécie canina nas raças Bulldog Inglês e Francês (SORRIBAS, 2009; ROBERTS, 1984; BUCHANAN, 2001; HOSKINS, 2006), Bichon Frise (ALLEN et al., 1989), Schnauzer, Chow-Chow (PADGETT at al, 1986) e Pequinês (CHEW-LIM, 1976). Outro estudo mais recente, relata a ocorrência em outras raças caninas como: Golden Retriever, Pug, Shih Tzu, Rottweiler, Malamute do Alaska, Fox Terrier e Labrador (HOPPER et al.,2004).

O exame ultrassonográfico é o procedimento de escolha para o diagnóstico confiável de hidropisia fetal em humanos. Em mais de $91 \%$ dos casos a ultrassonografia obstétrica foi capaz de detectar pelo menos uma alteração compatível com o quadro (SILVA et al., 2005), pois o conhecimento da anormalidade é de suma importância e significativo para a instituição terapêutica e o estabelecimento do prognóstico (HOPPER et al., 2004). Na espécie canina, apesar do uso do exame ultrassonográfico durante o pré-natal ainda não ser de rotina, alterações como desenvolvimento anormal do feto (ZEO; MOLINA, 2006), e hidropisia, podem ser diagnosticada por ultrassonografia (SORRIBAS, 2009; BUCHANAN, 2001). Porém, alguns autores salientam que este exame pode não ser totalmente preciso na triagem de uma anomalia fetal, devido à imprecisão na identificação de todos os fetos numa fase tardia da gestação (ALLEN et al., 1989; ENGLAND, 1998).

$\mathrm{Na}$ medicina humana, apesar dos avanços diagnósticos e terapêuticos, a hidropsia fetal ainda é uma enfermidade com altas taxas de letalidade, a maioria das crianças são natimortas ou morrem nas primeiras horas de vida (SILVA et al., 2005). Um estudo em humanos relata a realização da paracentese guiada pelo ultrassom do líquido ascítico, para fins propedêuticos e terapêuticos, devido à excessiva compressão torácica causada pelo líquido peritoneal (BOTELHO et al., 2006). Já na medicina veterinária apesar da gestação geralmente chegar a termo, esse quadro é praticamente incompatível com a vida (LONG, 2001; ENGLAND 1998). Assim como na medicina humana há relatos de tratamento dessa enfermidade logo após a cesariana, tratamento esse baseado na aplicação de diuréticos e reposição de potássio (HOSKINGS, 2006).

HOPPER (2004), diagnosticou e acompanhou todo o período gestacional de fetos caninos com hidropisia, em alguns casos houve resolução espontânea do quadro, porém, nos casos de gestação que vieram a termo, os fetos eram natimortos ou vinham a óbito horas após o nascimento, mesmo com a terapia instituída.

\section{Descrição do caso}

Uma fêmea da espécie canina da raça Poodle de 18 meses de idade, com 40 (quarenta) dias de gestação foi atendida no Hospital Veterinário "Vicente Borelli" (HOVET), do Centro Universitário da Fundação de Ensino Octávio Bastos, para realização de um exame ultrassonográfico pré-natal, no intuito de avaliar o desenvolvimento e a viabilidade fetal. Ao ser realizado o exame ultrassonográfico foi detectada a presença de quatro fetos; sendo que um deles apresentava bradicardia (164 batimentos por minuto), tamanho diferenciado (maior em relação aos demais), presença de efusão pleural e 
peritoneal caracterizando uma anomalia fetal (Figura 1). Os outros fetos identificados apresentavam batimentos cardíacos (média 200 batimentos por minuto) e desenvolvimento dentro dos padrões de normalidade.

Devido a incompatibilidade do tamanho do animal foi efetuada a indicação de que o proprietário retornasse para realização da cesariana em 15 (quinze) dias. Na noite anterior a data marcada o animal havia entrado em trabalho de parto parindo dois filhotes, cessando então os sinais de parto e as contrações. Foi então encaminhado para a cesariana onde diagnosticou-se distocia causada pelo feto hidrópico que apresentava peso de 248 gramas (Figura 2) sendo que os demais pesaram em torno de 160 a 170 gramas. (Figura 3 )

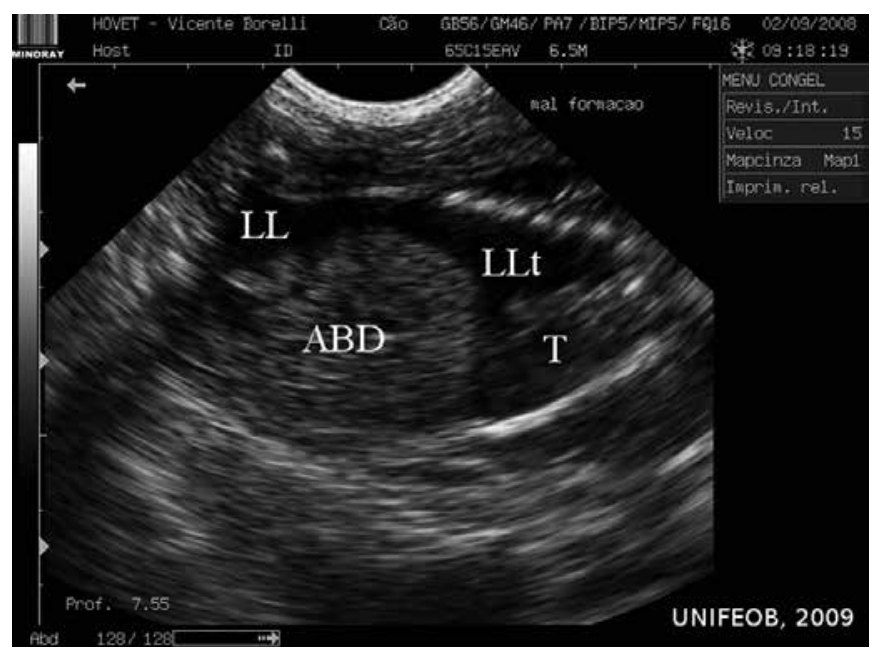

Figura 1 - Imagem ultrassonográfica demonstrando feto com presença de líquido torácico e peritoneal $(L L=$ líquido livre peritoneal; $\mathrm{LLt}=$ líquido livre torácico; $\mathrm{T}=$ tórax; $\mathrm{ABD}=\mathrm{Abdômen)}$.

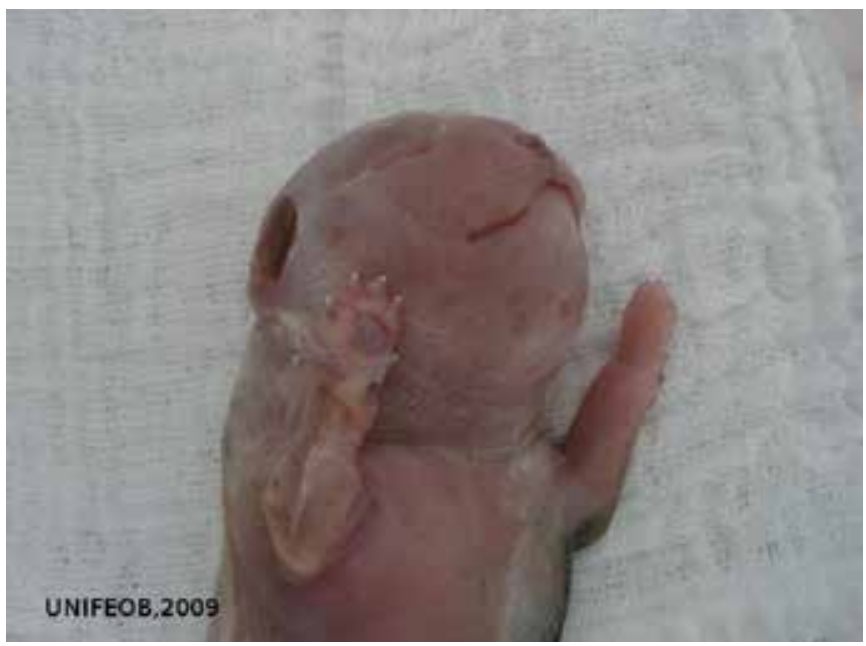

Figura 2 - Recém-nascido hidrópico apresentando tamanho e peso acima do normal.

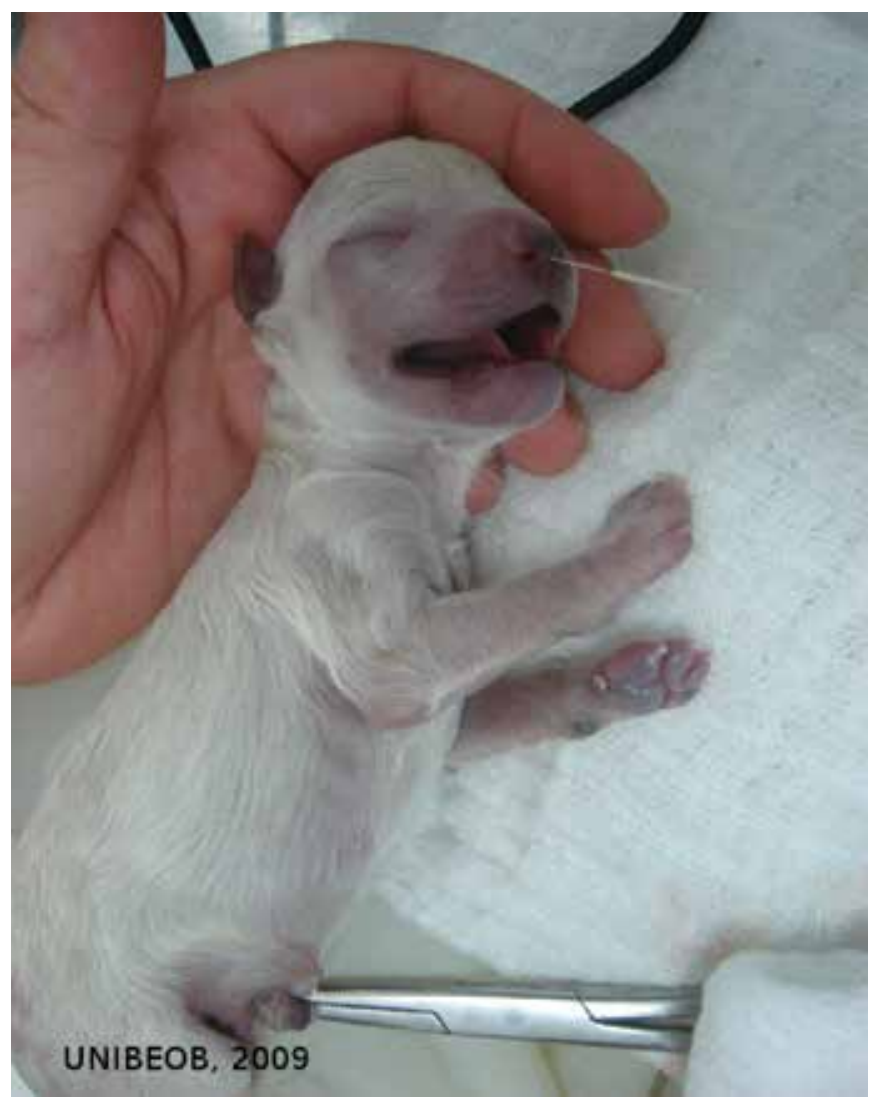

Figura 3 - Recém-nascido de tamanho e peso normal.

O filhote hidrópico veio a óbito nos primeiros minutos após o nascimento, sendo diagnosticado como hidropisia do tipo anasarca. Ao exame necroscópico o animal apresentou, além do edema generalizado, efusão peritoneal (ascite), efusão pleural, hidrocefalia (Figura 4A e B), congestão hepática e esplênica,

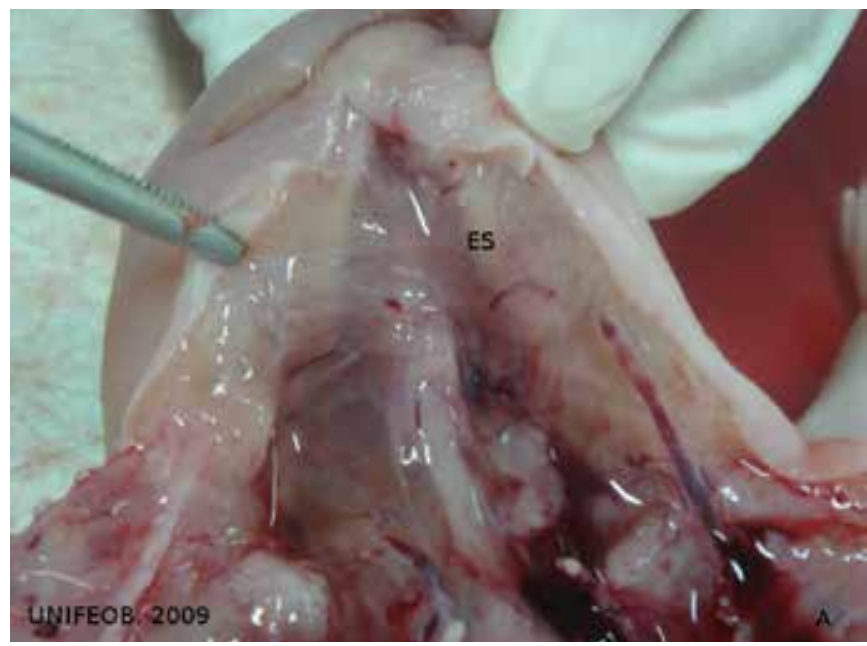

Figura 4A - Filhote ao exame necroscópico, apresentando edema de subcutâneo generalizado. 


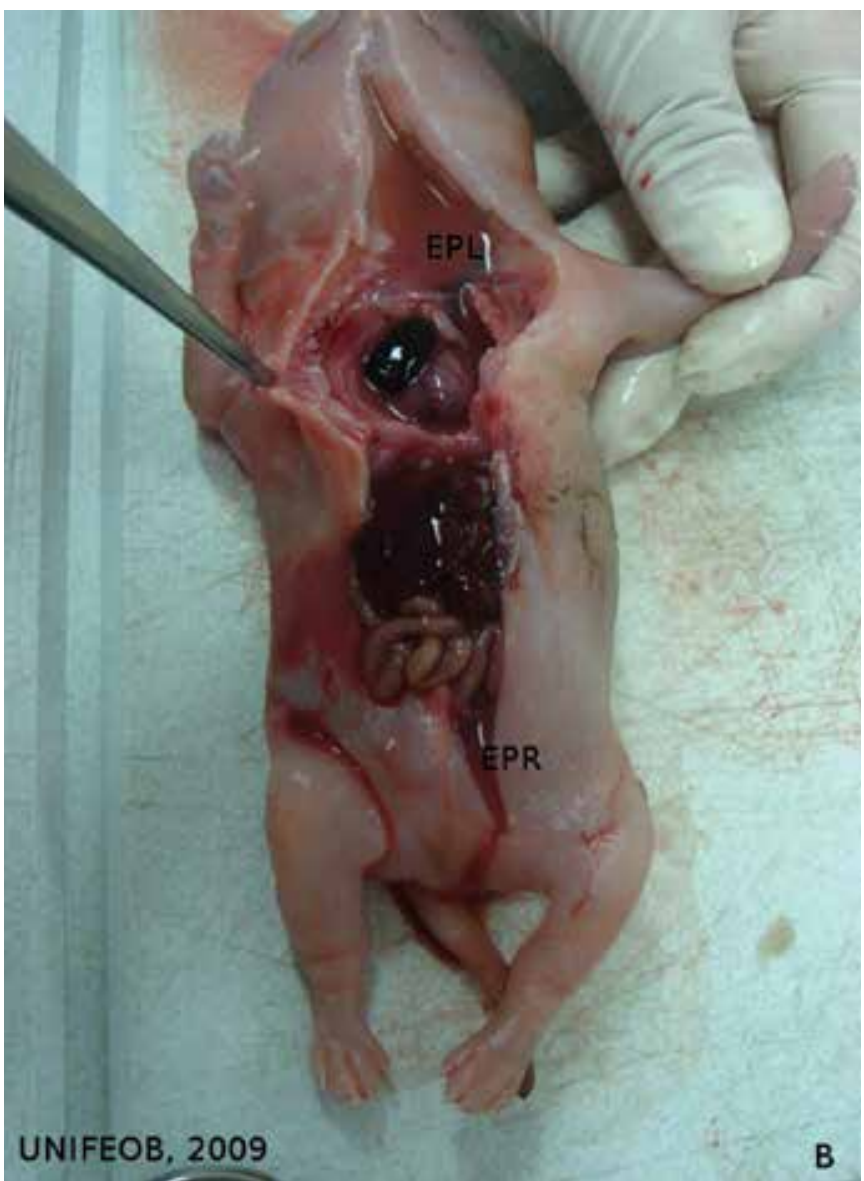

Figura 4B - Filhote ao exame necroscópico apresentando efusão pleural (EPL) e efusão peritoneal (EPR).

pulmões colabados, caracterizando uma falha no desenvolvimento fetal.

Apesar das diversas etiologias possíveis, neste caso acredita-se que a causa provável da hidropisia seja o cruzamento consanguíneo ocorrido nesta gestação.

\section{Discussão e conclusão}

Assim como descrito por ARTHUR, 1979; NOAKES, 2001; SORRIBAS, 2009, o feto hidrópico causou a distocia sendo necessária a realização da cesariana. Após o procedimento, foi possível a confirmação das alterações visualizadas ultrassonográficamente, edema generalizado de tecidos e membranas fetais.

Ao exame necroscópico foi observado hidrocefalia, congestão hepática e esplênica, alterações essas que não foram detectadas por meio do exame ultrassonográfico, mas concordam com autores que relatam a associação da anasarca com deficiência de desenvolvimento do feto afetado (TONIOLLO e VICENTE, 2003).
Assim como efetuado por Allen (1989) e Hopper (2004), no presente trabalho foi possível a demonstração da deficiência para o diagnostico da congestão dos órgãos fetais e hidrocefalia, mas não das cavidades torácica e abdominal. Os maiores problemas encontrados para avaliação dos órgãos fetais foram o grande número de fetos em uma fêmea pequena, limitação do aparelho utilizado e a agitação do animal.

Apesar da hidrocefalia não ter sido diagnosticada por ultrassom, esse estudo mostra, assim como outros (SORRIBAS, 2009; ALLEN, 1995; ALLEN et al., 1989; ZEO et al., 2006), que o exame ultrassonográfico é de suma importância para a avaliação pré-natal de rotina, pois possibilita que o médico veterinário acompanhe o desenvolvimento fetal e detecte precocemente anomalias fetais como a hidropisia. Pois, na atualidade, sem esse recurso, as anormalidades fetais só são diagnosticadas, mais comumente, após o parto.

\section{Referências}

1. ALLEN, W.E. Fertilidade e obstetrícia no cão. São Paulo: Livraria Varela, 1995.

2. ALLEN, W. E., ENGLAND, G. C. W., WHITE, K. B. Hydrops fetalis diagnosed by real-time ultrasonography in a bichon fries bitch: case report. Journal of Small Animal Practice, v. 30, p. 465-467, 1989.

3. ARTHUR, G. H. Reprodução e obstetrícia em Veterinária. Rio de Janeiro: Guanabara Koogan S.A., 1979, p.103-109.

4. BOTELHO, M. J.; ALVES, Z. E. F.; FERRI, S.; SALLES, E. P. Paracentese fetal para tratamento de hidropisia fetal não imunitária por provável reativação de infecção por citomegalovírus. Revista da Sociedade de Ginecologia e Obstetrícia. Jun./Jul., 2006.

5. BUCHANAN, J. W. Pathogenesis of single right coronary artery and pulmonic stenosis in English Bulldogs. Journal. Veterinary Internal Medicine, v.15, n.2, p.101-104, 2001

6. CHEW-LIM, M. Hydrocephalus and anasarca in a Pekingese litter. Veterinary Record, v.99, p.424-425, 1976.

7. ENGLAND, G. C. W. Ultrasonographic assessment of abnormal pregnancy. Veterinary Clinics of North America: Small Animal Practice, v.28, n.4, p.849-867, 1998.

8. HOPPER, B. J.; RICHARDSON, J. L.; LESTER, N. V. Spontaneous antenatal resolution of canine hydrops fetalis diagnosed by ultrasound. Journal of Small Animal Practice, v.45, n.2, p.8, 2004.

9. HOSKINS, J. D. Neonatologia del cachorro y el gatito. In: WANKE, M. M.; GOBELLO, C. Reproduccion em caninos y felinos doméstico. 1.ed. Buenos Aires: Inter-Médica, n.19, p.235-246, 2006.

10. 2- LONG, S. Abnormal development of the conceptus and its consequences Dropsy of the fetal membranes an fetus. In: NOAKES, D. E.; PARKINSON, T. J.; ENGLAND, G. C. Arthur's Veterinary Reproduction and Obstetrics. Saunders - Elsevier Limited, 8. ed., p.119-143, 2001.

11. NOAKES, D. Dystocia due to twins or monstrosities. In: NOAKES, D. E.; PARKINSON, T. J.; ENGLAND, G. C. Arthur's Veterinary Reproduction and Obstetrics. 8. ed. Saunders - Elsevier Limited, v.17, p.313-317, 2001 
12. PADGETT, G. A.; BELL; T., PATTERSON; W. R. Genetic disorders affecting reproduction and periparturient care. Veterinary Clinics of North America, v.16, p.577-586, 1986.

13. ROBERTS, S. J. Obstetrícia Veterinária y Patologia de La reproduccion (Teriogenologia). Buenos Aires: Editorial Hemisferio Sur S.A., 1984.

14. SILVA, A. R. A.; ALZEGUIR, J. C. L.; COSTA M. C. F. L.; TRISTÃO, M. A. P.; NOGUEIRA, S. A.; NASCIMENTO, J. P. Hidropisia fetal: análise de 80 casos. Revista Brasileira de Ginecologia e Obstetetrícia, v.27, n.3, p.143-148, 2005.
15. SORRIBAS, C. E. Manual de emergências e afecções frequentes do aparelho reprodutor em cães. 1. ed. São Paulo: MedVet, 2009.

16. TONIOLLO, G. H.; VICENTE, W. R. R. Manual de obstetrícia veterinária. São Paulo: Livraria Varela, p.57-60, 2003.

17. ZEO, G. B.; MOLINA; E. M. Uso de La ultrasonografia en el aparato reproductor In: WANKE, M. M.; GOBELLO, C. Reproduccion em caninos y felinos domésticos. $1^{\circ} \mathrm{ed}$. Buenos Aires: Inter-Médica, v.13, p.159-173, 2006. 